\section{Promoviendo la investigación y proyección social en estudiantes de Odontología}

\section{Promoting research and social projection in Dentistry students}

\section{Sr. Editor}

En el Perú existen 143 universidades de las cuales 59 ya están licenciadas por la Superintendencia Nacional de Educación Superior Universitaria (SUNEDU) ${ }^{1}$, de estas, 41 universidades ofrecen la carrera profesional de Odontología, siendo denominada en algunos casos como Estomatología ${ }^{2}$. Esto refleja la gran oferta que aún presenta la profesión odontológica en desmedro de la verdadera demanda que hoy en día requiere la nación.

La educación superior universitaria peruana se encuentra en proceso de cambios y muchas universidades y programas académicos requieren adaptarse a las "Condiciones Básicas de Calidad" para el licenciamiento universitario. Dentro de las actividades que se necesitan realizar para alcanzar tal licenciamiento se encuentra que la universidad presente "líneas de investigación" y que "la universidad desarrolle actividades de investigación bajo la dirección de sus docentes y estudiantes, de modo que se genere un ambiente propicio para la creación de conocimientos" ${ }^{3}$. Estos cambios se vienen dando con la finalidad de aumentar la producción científica nacional y permitir que los estudiantes desarrollen capacidades investigativas que permitan solucionar problemas de una comunidad.

Tanto en Medicina humana como en la Odontología peruana la producción científica por parte de estudiantes del pregrado es muy baja ${ }^{4,5}$. La participación estudiantil en las actividades de producción del conocimiento científico aún no logra consolidarse como una de las funciones de la educación superior, aún la investigación científica sigue centrándose en los docentes ordinarios y los posgrados.

Las universidades son los centros responsables de promover la investigación en los estudiantes ya que son la cuna de las grandes ideas innovadoras. Con el propósito de fomentar la investigación y proyección social en los estudiantes del pregrado se crearon las sociedades científicas estudiantiles como organizaciones sin fines de lucro ni político. Una de las primeras sociedades científicas estudiantiles en Perú fue la Sociedad Científica San Fernando (SCSF) fundada el 7 de junio de 1991 por los estudiantes del pregrado de la Facultad de Medicina de la Universidad Nacional Mayor de San Marcos (UNMSM). Actualmente, existen en nuestro país 44 Sociedades Científicas de Estudiantes de Medicina (SOCIEMS), 37 de ellas están afiliadas a la Sociedad Científica Médico Estudiantil Peruana
ISSN: 1560-9111

\section{Cartas al Editor}

Kamila Sihuay-Torres ${ }^{1, a}$, Yuri Castro-Rodríguez ${ }^{2, b}$

1 Universidad Nacional Mayor de San Marcos.

Facultad de Odontología. Lima, Perú.

2 Universidad Privada Juan Pablo II. Dirección

de Investigación. Lima, Perú.

a Bachiller en Odontología.

${ }^{\mathrm{b}}$ Magíster en Educación.

\section{Correspondencia:}

Kamila Sihuay-Torres

Correo electrónico: kamila.sihuay28@gmail.com Ca. Marcelino Varela 378 Los Ficus, Santa Anita. Lima, Perú.

\section{Coautor:}

Yuri Castro Rodríguez

yuricastro_16@hotmail.com

Conflicto de intereses: Kamila Sihuay-Torres es miembro activo y past presidente de la SCEO-UNMSM. Yuri Castro-Rodríguez es asesor científico de la SCEO-UNMSM.

Fecha de recepción: 25/01/19 Fecha de aceptación: 08/02/19 
(SOCIMEP) fundada en $1992^{6}$, y siete están en proceso de afiliación.

Los alumnos del pregrado de la Facultad de Odontología de la UNMSM en su afán por continuar y contribuir con esta idea, fundaron la Sociedad Científica de Estudiantes de Odontología (SCEO-UNMSM) a inicio del ańo 2014, teniendo como modelo la SCSF. Por el momento es la única sociedad científica de estudiantes de odontología que funciona en nuestro país pese al sistema burocrático de la universidad por su aprobación formal. La SCEO-UNMSM se organiza en cuatro comités que buscan promover la investigación científica y proyección social en los estudiantes de pregrado: Comité Permanente Científico Académico, Comité Permanente de Atención Estomatológica, Comité Permanente de Ediciones y Publicaciones, y Comité Permanente de Relaciones Interinstitucionales e Intercambios. Cada comité presenta sus reglamentos y tienen como finalidad producir conocimientos, difundirlos y participar en actividades de proyección y extensión social.

En tan solo cuatro años, la SCEO-UNMSM ha logrado publicar 14 artículos científicos (seis de los cuales se encuentran indizados en la base de datos Scopus) (Tabla), ha logrado participar en siete congresos científicos, de los cuales ha obtenido los primeros lugares en cinco de los concursos de póster y mesas clínicas, ha logrado editar un boletín científico que es publicado dos veces al año en la página oficial de la sociedad (https://www.fa-
cebook.com/SCEOUNMSM/), también ha logrado difundir actividades inéditas denominadas "Mythbusters" (un segmento donde se discute los mitos de la investigación científica), "Odontocuriosidades" (segmento donde se resume descubrimientos curiosos de la odontología y medicina) y el "Tip científico" (segmento donde se sintetiza los aspectos más relevantes de la metodología de la investigación). Todas estas actividades y producción científica se han realizado con el afán de incentivar a los estudiantes de pregrado de nuestra facultad y de las demás universidades para que la idea de la SCEO se difunda y permita a los estudiantes ser partícipes de su formación en las competencias investigativas.

Consideramos que si un estudiante desea aprender a investigar la única forma posible de lograrlo es investigando. De esta forma, en la SCEO-UNMSM se están otorgando los espacios necesarios para que los estudiantes junto con docentes investigadores puedan planificar estudios, ejecutarlos en conjunto y difundirlos a través de revistas científicas.

Con la presente carta queremos dar a conocer la importancia de esta agrupación estudiantil para que sea difundida en nuestro país, motivando a los estudiantes y autoridades de las otras facultades de Odontología para que apoyen, incentiven y promuevan la creación de estas sociedades estudiantiles. De esta manera la investigación en nuestra profesión progresará y nuestra sociedad también.

Tabla. Publicaciones científicas realizadas por la SCEO - UNMSM

\begin{tabular}{|c|c|c|c|}
\hline Año & Título del artículo & Nombre de la revista & Base de datos \\
\hline 2016 & $\begin{array}{l}\text { Efecto antiinflamatorio del extracto acuoso de oenothera rosea en ratas } \\
\text { con edema subplantar inducido por carragenina. }\end{array}$ & $\begin{array}{l}\text { Journal of the Peruvian Association of } \\
\text { Periodontology and Osseointegration }\end{array}$ & No indizada \\
\hline \multirow[t]{3}{*}{2017} & $\begin{array}{l}\text { Percepción del ambiente educacional por estudiantes del pregrado en } \\
\text { odontología. }\end{array}$ & Educación Médica & Scopus \\
\hline & $\begin{array}{l}\text { Propiedades psicométricas del Dundee Ready Education Environment } \\
\text { Measure en la Odontología }\end{array}$ & Educación Médica & Scopus \\
\hline & Estudio in vitro de la relación entre el foramen apical y ápice anatómico & Odontología Sanmarquina & No indizada \\
\hline \multirow[t]{9}{*}{2018} & $\begin{array}{l}\text { Producción científica y percepción de la investigación por estudiantes } \\
\text { de odontología }\end{array}$ & Educación Médica & Scopus \\
\hline & $\begin{array}{l}\text { Producción científica de tesis sustentadas y publicadas por estudiantes } \\
\text { de odontología. }\end{array}$ & Educación Médica & Scopus \\
\hline & $\begin{array}{l}\text { Exactitud del sondaje periodontal según observadores y } \\
\text { tipos de sondas periodontales }\end{array}$ & Acta Odontológica Colombiana & EBSCO \\
\hline & Percepción del plagio académico en estudiantes de Odontología. & Educación Médica & Scopus \\
\hline & Ambiente educacional durante las prácticas hospitalarias & Investigación en Educación Médica & ScienceDirect \\
\hline & $\begin{array}{l}\text { Características morfométricas de los dientes multirradiculares a nivel } \\
\text { de la zona de furcación }\end{array}$ & Odontoestomatología & SciELO \\
\hline & $\begin{array}{l}\text { Percepción del blended learning en el proceso enseñanza aprendizaje } \\
\text { por estudiantes del posgrado de Odontología. }\end{array}$ & Educación Médica & Scopus \\
\hline & $\begin{array}{l}\text { Relación entre la entrada de la furca dentaria y el ancho de las curetas } \\
\text { periodontales. }\end{array}$ & Revista Mexicana de Periodontología & No indizada \\
\hline & $\begin{array}{l}\text { Estimación del peso según la edad. Comparación de las fórmulas en } \\
\text { una muestra peruana }\end{array}$ & Odontología Sanmarquina & No indizada \\
\hline
\end{tabular}




\section{Referencias bibliográficas}

1. SUNEDU [Internet]. Universidades Licenciadas. [Consultado el 21 de enero del 2019]. Disponible en: https:// www.sunedu.gob.pe/lista-de-universidades-licenciadas/ https://www.sunedu.gob.pe/lista-de-universidades-licenciadas/

2. Colegio Odontológico del Perú [Internet]. Directorio de Facultades de Odontología. [Consultado el 21 de enero del 2019]. Disponible en: http://www.cop.org.pe/directorio-de-facultades-de-odontologia

3. SUNEDU [Internet]. El Modelo de Licenciamiento y su Implementación en el Sistema Universitario Peruano.
[Consultado el 21 de enero del 2019]. Disponible en: https://www.sunedu.gob.pe/condiciones-basicas-de-calidad/

4. Castro RY, Sihuay-Torres K, Perez-Jiménez V. Producción científica y percepción de la investigación por estudiantes de odontología. Educ Med. 2018;19(1):19-22.

5. Taype-Rondán Á, Palma-Gutiérrez E, Palacios-Quintana M, Carbajal-Castro C, Ponce-Torres C. Producción científica estudiantil en Latinoamérica: un análisis de las revistas médicas de habla hispana indizadas en SciELO, 2011. Rev Fund Educ Med. 2014:17(3):171-7.

6. SOCIMEP [Internet]. Sociedades Científicas de Estudiantes de Medicina. [Consultado el 22 de enero del 2019]. Disponible en: https://www.socimep.net. 